\title{
Development of A Small/ Medium Scale Grading System
}

\author{
D M S P Bandara, H M A P Rathnayake and M D Fernando
}

\begin{abstract}
This study was undertaken to develop appropriate and low cost grading device for a variety of economically important agricultural produce, in order to increase their market demand. This grader was tested for tomato with three grades which raise the value of the produce significantly due to that worked on the principle of rolling the produce around the axis of minimum mass inertia was evaluated. Two grades were separated based on the opening size and a third grade consisted of produce that overflowed the largest opening. The opening for grade I, II and III were $55 \mathrm{~mm}$ to $65 \mathrm{~mm}, 65 \mathrm{~mm}$ to 75 $\mathrm{mm}$ and $>75 \mathrm{~mm}$ respectively. The grader was tested for tomatoes at slope of 08 degrees, 10 degrees and 12 degrees and the 10 degree was the best slope. The rates for which the grader was tested were 192 $\mathrm{kg} / \mathrm{h}, 288 \mathrm{~kg} / \mathrm{h}$ and $576 \mathrm{~kg} / \mathrm{h}$ and the percentage of tomato correctly graded were $90 \%, 89 \%$ and $72 \%$ at slope of ten degree respectively.
\end{abstract}

Keywords: Agro Processing, Grading, Machinery, Graders

\section{Introduction}

Within the domestic food sector or non-plantation agriculture sector, the paddy cultivation plays an important role, as rice is the stable food for the nation. The main policy driven is to achieve self-sufficiency in paddy production. Next to paddy sector, the perishable sub sector is the most prominent in the agriculture sector, as vegetables/fruit are grown throughout the country and large number of farmers are involved in vegetable/fruit cultivation.

As being a poor and developing country, Sri Lanka is facing many problems in the agriculture system, especially in marketing of the agricultural produce. The majority of farmers in Sri Lanka are poor and ignorant. And the high tech practices are less available or cannot be afforded. Therefore, they are still using improper techniques in cultivation as well as in post harvest practices, which lead to a low profit and a low market value for their produce.

The grading and sorting techniques have to be done after harvesting as a method for value addition. This can be done according to the size, variety, color, maturity, presence of pests and diseases, etc. This will minimize the physical damages and spread of pest and disease spread; eventually giving a high profit and market value. In Sri Lanka sorting and grading of fruit and vegetable to some extent is being practiced but very less in vegetables unless at super market level. For export or processing some vegetable and fruits have to be graded for size and quality. After grading, the different sizes of produce could be sold in different rate of prices. The normal grading is being done manually which is time consuming. Due to unavailability of proper sorting and grading devices or grading houses and lack of knowledge and interest, this practice is not been done effectively.

Especially tomatoes (Solanum lycopersicum), mangoes (Mangifera) and passion fruit (Passiflora) are sold in the market without grading in Sri Lanka. If those were sold after grading, this would be beneficial to both producers and consumers.

To give the different prices for the same harvest in different sizes such as tomato, mango, orange, those have to be graded for size and quality. Further operation for grading of those agricultural produce is done manually, it is a labor consuming.

Therefore, this study was undertaken to develop appropriate and low cost grading devices for a variety of economically important agricultural produce such as passion fruit, mango and tomato, in order to increase their market demand. The main objective of this study was

Eng. (Ms). D.M.S.P. Bandara, B.Sc.Eng., MEng, AMIE(Sri
Lanka), NSF/STMIS/O9/2466, Mechanical Engineer, Institute
of Post Harvest Technology, Anuradhapura, Sri Lanka.
Eng. H.M.A.P.Rathnayake, B.Sc.Eng. M.Tech. (Ag. Eng.),
AMIE (Sri Lanka), Mechanical Engineer, Institute of Post
Harvest Technology (IPHT), Anuradhapura, Sri Lank
M.D. Fernando, M.Sc.Agric., MAACC, Director, Institute of
Post Harvest Teclmology (IPHT), Anuradhapura, Sri Lanka. 
to design and develop of appropriate and cost effective size separation mechanisms for grading of economically important agricultural produce and thereby to enhance the efficiency of the grading practices in the post harvest channel.

\section{Materials and Method}

Two grades were separated based on the size and a third grade consisted of produce that overflowed the largest opening. The opening for grade I, grade II and grade III were 55 to 65,65 to 75 and $>75 \mathrm{~mm}$ respectively.

The grader was made of locally available materials to heep the cost low. It was fabricated at the workshop of Engineering Division of Institute of Post Harvest Technology, Anuradhapura.

The grader consisted of a main structure as shown in Figure: 1 fabricated with MS angled bars. Eleven ${ }^{3 / 4}$ inch aluminium tubes fixed in both ends were used to make the converging opening of $55 \mathrm{~mm}$ at the feed end and $75 \mathrm{~mm}$ at discharge end and those facilitate the produce to flow over the flowing area properly. Anyway these openings are adjustable by moving bearing along the groove as desired according the variety and type of produce.
In this study, all the testing was carricd out using tomatoes. Graded Tomatoes collection mechanism is provision of plastic crates at each end of the collection chutes. Two persons were required to run the grader successfully. One person supplied tomatoes and other one drove the gear system to facilitate the rotation of aluminum tubes. Figure: 6 show the grader in operation.

The tomato was moved through grader and the percentage of fruit that moved through each opening which was correctly graded at three different feed rates was determined. The data were analyzed statistically by SAS and opening was determined by the best percent of tomato correctly graded

\subsection{Design of Main Structure}

The frame was made of $40 \mathrm{~mm} \times 40 \mathrm{~mm} \times 6 \mathrm{~mm}$ M.S angle bars. The main structure was fixed at 10 degrees angle to the horizontal after doing preliminary trials and the results were tabulated in Table: 1 and Table: 2. The dimension of the frame are shown in Figure 1.

\subsection{Design of grading table}

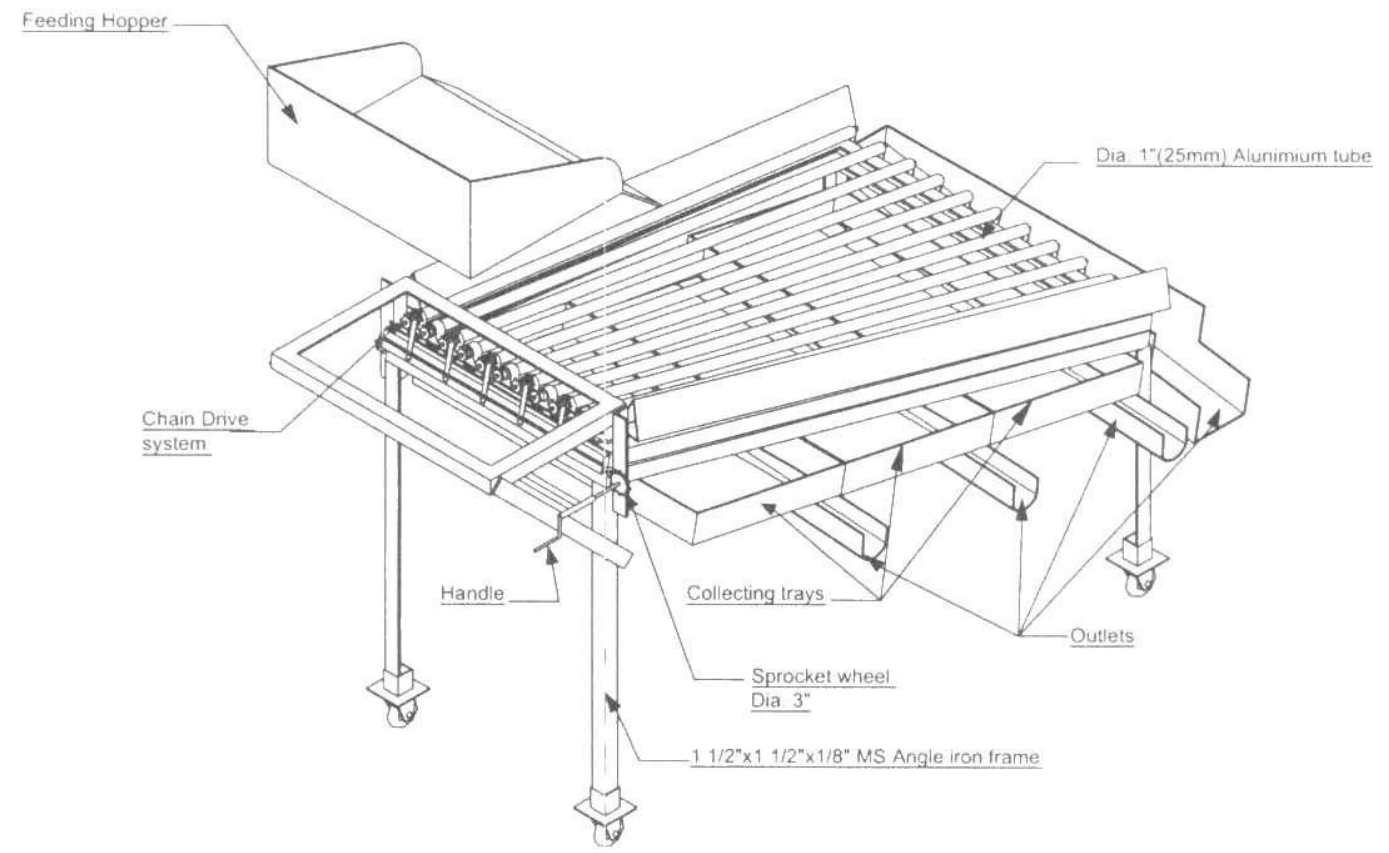

Figure 1: Main Structure of the Grader 


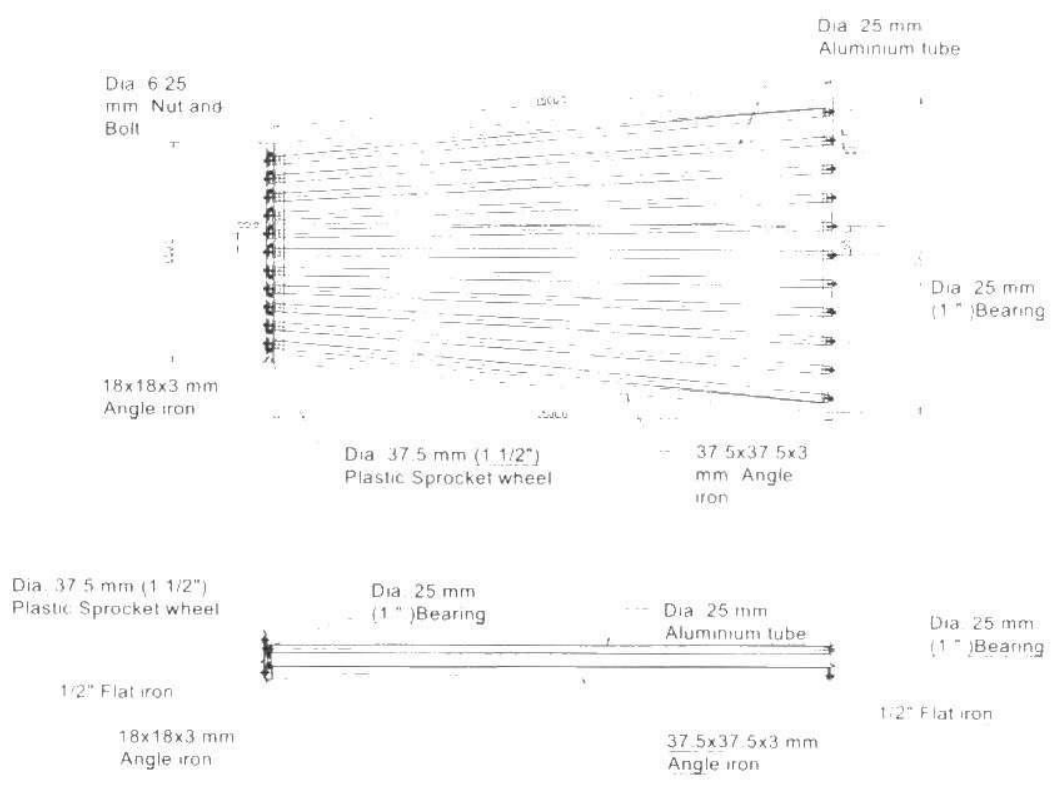

Figure 2: Fabricated grading table with Aluminum tubes

It is trapezium in shape due to converging effect of metal pipes with length $650 \mathrm{~mm}$ at the top and $930 \mathrm{~mm}$ at the bottom. Eleven light weight Aluminum metal pipes of diameter 24 $\mathrm{mm}$ and $1500 \mathrm{~mm}$ length are attached to $25 \mathrm{~mm}$ (608) plastic bearing. The pipes are arranged divergently with smaller opening of width 55 $\mathrm{mm}$ and large opening of width $75 \mathrm{~mm}$ at the ends. The motion to the pipes is given by rotating handle. The handle can be rotated manually or with the help of motor.

\subsection{Design of Hopper}

It was made out of plywood boards ( 18 gauges) in shape of traditional winnowing pan and placed on a rectangular frame made of MS angled bars.

\subsection{Design of Trays (Chutes)}

Collection chutes made out of plywood boards were provided and attached below the grading table. It is divided into 3 sections to collect the tomatoes of 3 grades. According to the preliminary result the collector is given inclination at 100 perpendicular to horizontal plane so that the tomatoes slide directly in crates through the outlets. The collector is partitioned with plywood sheets of 18 gauges to avoid mixing of tomatoes of different grades.

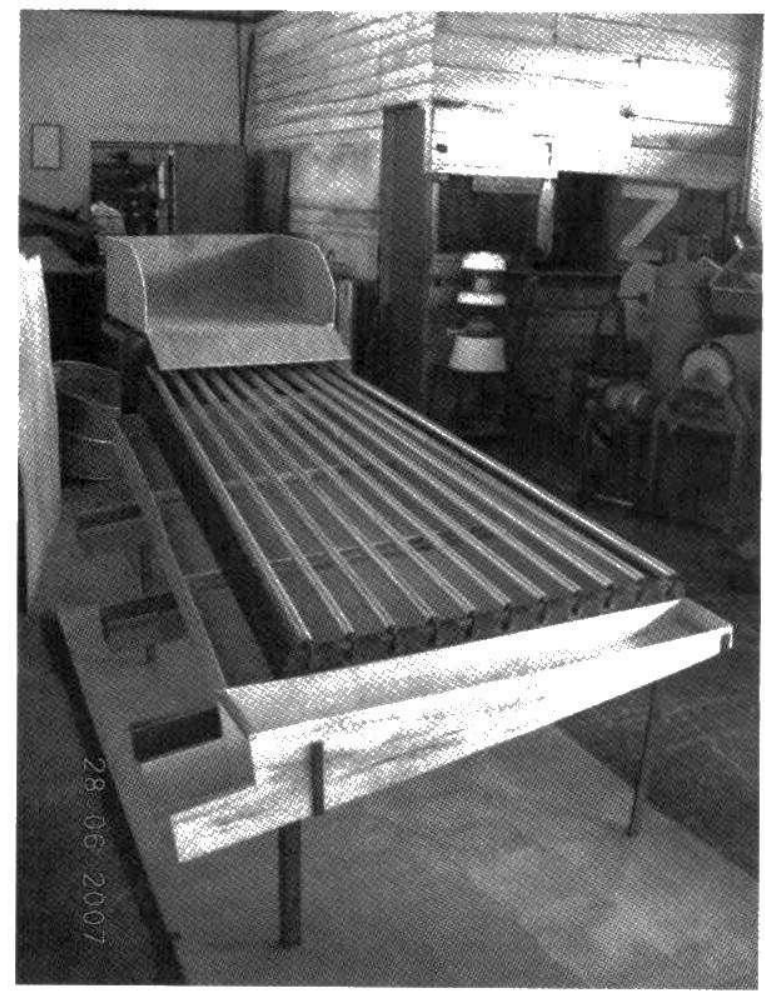

Figure 3: Fabricated chutes and hopper with plywood 


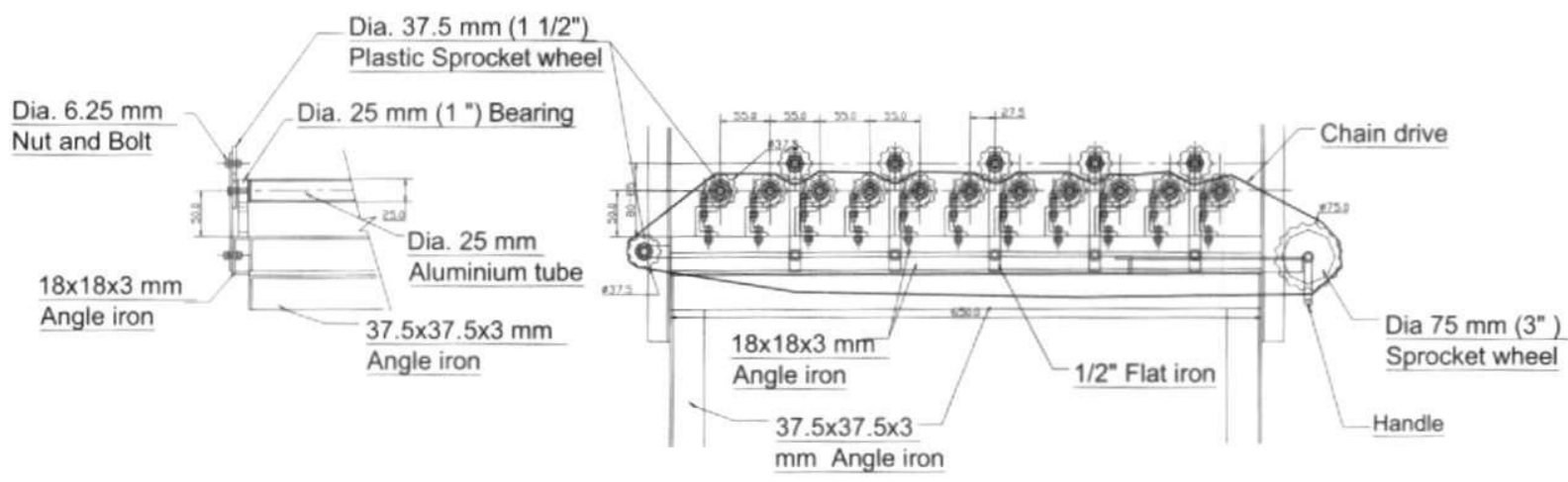

Figure 4: The grader driving system

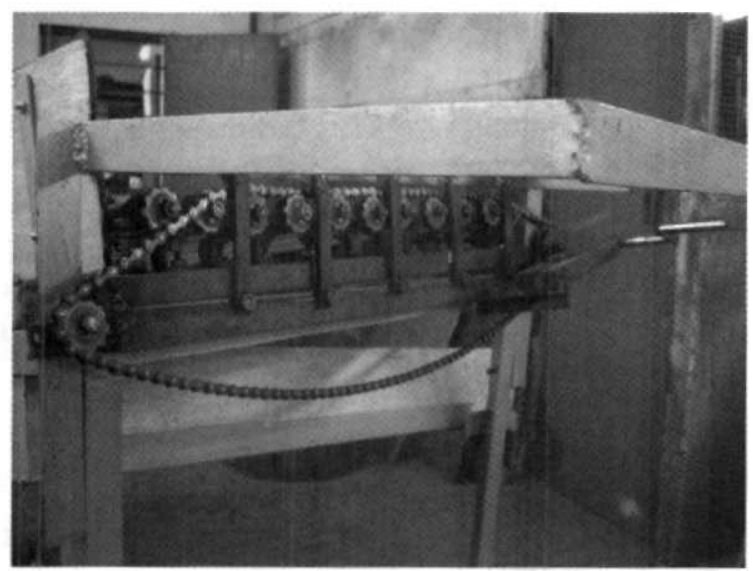

Figure 5: The grader driving system

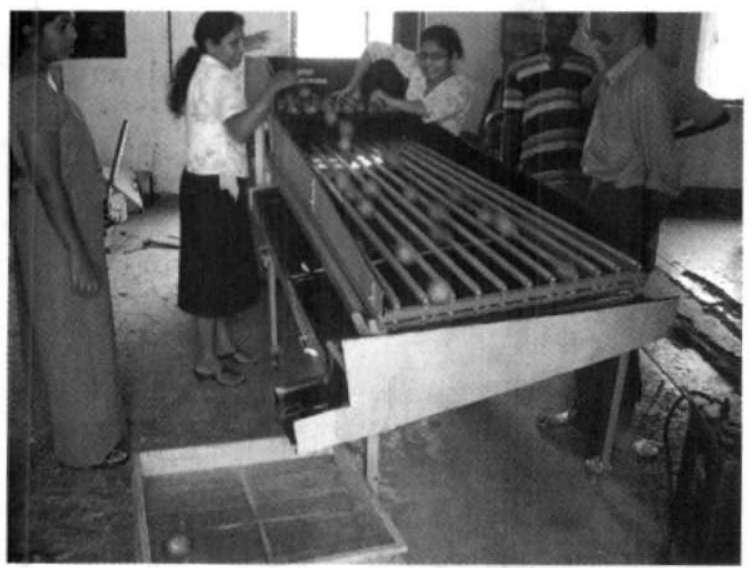

Figure 6: The IPHT grader in operation

\subsection{Cushioning material}

The chutes were covered with sponge sheets. In fact tomatoes bear the impact as they fall from slots in pipes upon the collector and are damaged in the process. The physical damage/injury to the tomatoes can be avoided by providing foam (5 mm thickness) on the collector. The foam is also pasted the hopper to avoid the initial impact too.

\subsection{Design of Gear assembly}

The plastic gears of diameter $37 \pm 2 \mathrm{~mm}$ are attached to metal pipes. Plastic gears further mesh with the gears upon the worm gears. The handle is attached to the sprocket gear of diameter $72 \mathrm{~mm}$ mounted on the main frame, which can be rotated manually, or motor driven. In this study, tubes were rotated manually at the average speed of

\subsection{Operation of Grader}

The tomatoes roll down the pipes due to gravity and fall immediately where they find the space of their diameter. Tomatoes fall in the collector which is partitioned into 3 sections for obtaining different grades of tomato i.e. 55 to 65,65 to 75 and $>75 \mathrm{~mm}$ and can be designed as grade I, II and III respectively (Fig 5). The collector is inclined at 100 perpendicular to the grading table so that the tomatoes slide directly in chutes. Tomatoes graded and collected in chutes were labeled as undersize, normal and oversize. The important feature of grader is its ability to adjust the gap between the pipes, inclination of grading table and hopper.

\section{Results and Discussion}

Table 1 shows the average percent of the correctly graded tomato that passed through opening for each of the three slope angle 8,10 and 12 degrees, respectively. 
Table 1: The percentage correctly graded tomato that passed through the each opening for the different slope at the rate of $288 \mathrm{~kg} / \mathrm{h}$

\begin{tabular}{|c|l|l|l|}
\hline \multirow{2}{*}{$\begin{array}{c}\text { Slope/ } \\
\text { (degrees) }\end{array}$} & \multicolumn{3}{|c|}{$\begin{array}{c}\text { The percentage correctly } \\
\text { graded/(\%) }\end{array}$} \\
\cline { 2 - 4 } & Grade I & Grade II & Grade III \\
\hline 8 & 70.00 & 91.66 & 100.00 \\
\hline 10 & 78.57 & 95.45 & 100.00 \\
\hline 12 & 63.63 & 96.15 & 100.00 \\
\hline
\end{tabular}

Table 2: The average percentage correctly graded tomato for the different slope at the rate of $288 \mathrm{~kg} / \mathrm{h}$

\begin{tabular}{|l|c|c|c|}
\hline & $\begin{array}{c}\text { Slope 1 } \\
\left(8^{0}\right)\end{array}$ & $\begin{array}{c}\text { Slope 2 } \\
\left(10^{0}\right)\end{array}$ & $\begin{array}{c}\text { Slope 3 } \\
\left(12^{0}\right)\end{array}$ \\
\hline $\begin{array}{l}\text { Ave. } \\
\text { percent } \\
\text { graded }\end{array}$ & $87.22(\mathrm{~B})^{\star}$ & $91.34(\mathrm{~A})^{\star}$ & $85.59(\mathrm{~B})^{\star}$ \\
\hline
\end{tabular}

"Any two means in the same raw followed by different letters differ significantly according to Duncan's multiple range test $(P<0.05)$.

Ten Degrees slope was found to be significantly $(p=0.0212)$ superior to 8 degrees and 12 degrees. It is possible that for the lower 8 degree slope which was almost flat the fruit was not rolling with sufficient velocity. Whereas, with the higher 12 degree slope, the fruits were reaching a higher velocity that caused them to over flow and collected as the third grade. Thus, both these cases resulted in a lower grading percentage. The intermediate 10 degree slope seemed to correct these deficiencies.

A single person manually operated the grader, the time taken for complete sorting of the sample was noted and the capacity of the machine per hour was calculated. [7]. Table: 3,4 and 5 show the percentage of the correctly graded tomato that passed through opening for each of the three feeding rates $192 \mathrm{~kg} / \mathrm{h}, 288 \mathrm{~kg} / \mathrm{h}$ and $576 \mathrm{~kg} / \mathrm{h}$ respectively.

Table 3: The percentage correctly graded tomato that passed through the each opening at a feed rate of $192 \mathrm{~kg} / \mathrm{h}$

\begin{tabular}{|l|l|l|l|c|}
\hline \multirow{2}{*}{} & \multicolumn{3}{|c|}{$\begin{array}{c}\text { The percentage correctly } \\
\text { graded/ (\%) }\end{array}$} & \multirow{2}{*}{} \\
\cline { 2 - 4 } & Grade I & Grade II & $\begin{array}{c}\text { Grade } \\
\text { III }\end{array}$ & \\
\hline & 82.96 & 85.73 & 100.00 & 89.56 \\
SD & 3.84 & 7.18 & 0 & (A) $^{*}$ \\
\hline
\end{tabular}

Table 4: The percentage correctly graded tomato that passed through the each opening at the feed rate of $288 \mathrm{~kg} / \mathrm{h}$

\begin{tabular}{|c|c|c|c|c|}
\hline & \multicolumn{3}{|c|}{$\begin{array}{l}\text { The percentage correctly } \\
\text { graded / (\%) }\end{array}$} & \multirow[t]{2}{*}{ Mean } \\
\hline & Grade I & Grade II & $\begin{array}{c}\text { Grade } \\
\text { III }\end{array}$ & \\
\hline SD & $\begin{array}{l}90.00 \\
6.57\end{array}$ & $\begin{array}{l}76.92 \\
6.83\end{array}$ & $\begin{array}{l}100.00 \\
0\end{array}$ & $\begin{array}{l}88.71 \\
(A)^{*}\end{array}$ \\
\hline
\end{tabular}

Table 5: The percentage correctly graded tomato that passed through the each opening at the feed rate of $576 \mathrm{~kg} / \mathrm{h}$

\begin{tabular}{|l|l|l|l|l|}
\hline \multirow{2}{*}{} & \multicolumn{3}{|c|}{$\begin{array}{c}\text { The percentage correctly } \\
\text { graded/ (\%) }\end{array}$} & \multirow{3}{*}{ Mean } \\
\cline { 2 - 4 } & Grade I & Grade II & $\begin{array}{c}\text { Grade } \\
\text { III }\end{array}$ & \\
\hline & 71.67 & 72.33 & 73.33 & 72.44 \\
SD & 2.89 & 3.21 & 1.53 & $(B)^{*}$ \\
\hline
\end{tabular}

*Any two means in the same row followed by different letters differ significantly according to Duncan's multiple range test $(\mathrm{P}<0.05)$.

For each of the three feed rates, the result was highly significant $(p=0.0001)$. But for the feed rate of $192 \mathrm{~kg} / \mathrm{h}$ and $288 \mathrm{~kg} / \mathrm{h}$, the percentage of correctly graded tomato was not significant (A). It shows that the correctly graded tomato was decreased with an increase in feed rate. The reason for such the decreased efficiency may have been that increased feed rate resulted in increased blocking of the grader opening and faster rolling of tomato which resulted in smaller tomato getting dropped into a larger category.

The present study revealed that the very time and labour consuming task of grading tomato can be greatly improved with the grader. And the trials upon the other fruits especially mango, passion fruits also were carried out. Of these fruits, passion fruits can be graded better, because this grading mechanism is well performed on round shaped produces. Main advantage of this grader is that the grader mechanism is adjustable according to the different size of produces 


\section{Conclusion}

The results obtained from the study are summarized and concluded as follows.

1. Machine was able to operate at the capacity of $576 \mathrm{~kg} / \mathrm{h}$ with the $72 \%$ grading efficiency

2. The highest grading efficiency $89 \%$ was obtained at the capacity of $288 \mathrm{~kg} / \mathrm{h}$

3. The suitable slope of grading table is $\mathbf{1 0 0}$ for grading tomatoes properly.

4. Because the operational methodology of this machine is the principle of rolling the produce around the axis of mininum mass inertia, any round shaped agricultural produce can be graded properly adjusting slope and sizes of opening of each grade according to the size of produce. It is recommended that testing had better do on other produces too.

5. The physical damage could not be observed during the testing period

\section{Acknowledgement}

Sincere thanks are due to Sri Lanka Council of Agricultural Research Policy (SLCARP) for financial support for this research project. Authors also like to acknowledge the services of other members of the Institute of Post Harvest Technology (IPHT) for their fullest corporation extended in this regards.

\section{References}

1. Fruit grader, Product catalogue 2006, Central Institute of Agricultural Engineering, Bhopal, India, p25

2. http:// www.foodpromachine.com Visited,4th February 2006.

3. http://www.indianindustry.com. Visited, 2nd October 2006

4. Kuprits, Ya.N., Technology of grain processing and provender milling, 1st ed., Israel Programme for scientific translation, Jerusalem, ,pp. 199,1965.

5. Roy K.C., Wohab W.A and Gulam Mustafa A.D.M. 2005. Design and Development of a low cost Potato Grader, AMA, volume 36, p 28-31
6. SAS Institute Inc.,SAS User's Guide: Statistics. SAS Institute Inc. Cary, NC, 1994

7. Syed Zameeer Hussain, Mandhar S.C and Javar Gowda S. 2005, Evaluation and performance of raw mango grader, AMA, volume 36, P 46-48

8. Pandey P.H., Principles \& Practices of Post Harvest Technology, 3rd ed, Kalyani publishers, New Delhi, 2004,274-294

9. Sahay,K.M., Singh, K.K., Unit Operations of Agricultural Processing, 2nd ed., Vikas Publishing House, Private Limited, New Delhi, 2005, pp219-287.

10. Pujra K., Junoja B.A., Bhandari A.C., Singh G. and Pujra R.S.; "Machine Design"; Dhanpat Rai \& Sons, New Delhi; 2nd edition, 1984.

11. Chapman W.A.J.; "Workshop Technology (Part 2)"; ELBS \& Edward Arnold (Publishers) Ltd.; 4th edition, 1972.

12. Colin Carmichael., "Kent's Mechanical Engineers Hand Book" 12th edition.,John Willey and Sons,Inc.,New York, 1950,pp

13. Earle, R.L., Unit Operation in Food Processing, 2nd ed.,Pergamon Press, Oxford, 1983, p. 159.

14. Robert.E.Machol.,Wilson. P., Tanner. J.R., Samual N. Alexander, "System Mechanical Hand Book"., Mcgbaw-hill Book Company., USA,965 